\title{
Cross hedging under multiplicative basis risk
}

\author{
Axel F.A. Adam-Müller ${ }^{a, *}$, Ingmar Nolte ${ }^{b}$ \\ ${ }^{a}$ Universität Trier, Fachbereich IV - BWL, D-54296 Trier, Germany \\ ${ }^{\mathrm{b}}$ Warwick Business School, Finance Group, Coventry CV4 7AL, United Kingdom
}

\section{A R T I C L E I N F O}

\section{Article history:}

Received 13 October 2010

Accepted 27 March 2011

Available online 13 April 2011

\section{JEL classification:}

D81

G11

G32

Keywords:

Risk management

Cross hedging

Basis risk

Prudence

Jet fuel

Crude oil futures

Vector error correction model

\begin{abstract}
A B S T R A C T
Cross hedging price risk in an incomplete financial market creates basis risk. We propose a new way of modeling basis risk where price risk and basis risk are combined in a multiplicative way. Under this specification, positive prudence is a necessary and sufficient condition for underhedging in an unbiased market. Using the example of cross hedging jet fuel price risk with crude oil futures, we show that the new specification is superior in describing the price series and that optimal cross hedges differ significantly from those derived under the traditional additive cross hedging model.
\end{abstract}

(c) 2011 Elsevier B.V. All rights reserved.

\section{Introduction}

In an incomplete financial market, hedging instruments that perfectly mirror a given price risk are not always available. In these cases, the hedger has to manage price risk with a cross hedge. This creates basis risk. There are numerous examples for financial decision problems of this kind: If the composition of an equity portfolio differs from the composition of the market index and the investor hedges with index futures, there will be basis risk. The same applies to a farmer growing a particular grade of corn when the hedging instrument relates to another grade of corn. Investment banks also bear basis risks when they sell customized derivatives products to corporate clients and cross hedge with standardized exchange-traded financial derivatives. As there are hardly any derivatives on jet fuel, an airline's risk management has to resort to contracts on other oil products such as crude oil. Consequently, an airline is exposed to basis risk when managing jet fuel price risk.

This paper focuses on how the nature of basis risk affects the optimal cross hedge. Most cross hedging models assume that the spot price is equal to the futures price or forward price plus a noise

\footnotetext{
* Corresponding author. Tel.: +49 651201 2725; fax: +49 6512013841.

E-mail addresses: adam-mueller@uni-trier.de (A.F.A. Adam-Müller), ingmar nolte@wbs.ac.uk (I. Nolte).
}

term that captures basis risk. Since Benninga et al. (1983), this additive type of dependence has been used extensively in theoretical cross hedging studies. ${ }^{1}$ For any risk-averse decision maker and any volatility of basis risk, the optimal cross hedge in an unbiased futures market is a full hedge. (Briys et al. (1993) derive the optimality of an underhedge assuming the reverse relationship where the futures price is a linear function of the spot price and basis risk.) Under additive basis risk, the amount of basis risk is independent of the level of the futures price or the spot price. Apart from the analytical convenience and the striking elegance of the results achieved, it is difficult to justify this assumption. In particular, the assumption of additive basis risk is unsatisfactory because the economic conflict between managing price risk and, in doing so, generating basis risk is basically defined away in the first place. Hence, the economic conflict remains hidden so that it is not surprising that the optimal decision is the same no matter whether basis risk is small or large.

As an alternative, we propose a multiplicative relationship between basis risk and the futures or spot price. Consequently, the amount of basis risk is no longer independent of the price level but is proportional to it. We analyze two types of multiplicative

\footnotetext{
1 See Benninga et al. (1984), Broll et al. (1995), Chang and Wong (2003), among others.
} 
dependence: In the first type, the spot price is the product of the futures price and a conditionally independent basis risk. This specification is consistent with the log-log model that is widely used in the empirical literature on futures pricing. The second type is based on the reverse assumption: The futures price is the product of the spot price and an independent basis risk. This reverse assumption is consistent with the standard approach to futures pricing. Both assumptions seem particularly attractive when correlations between prices behave asymmetrically in that correlations are higher in a market downturn than in an upturn. (Ang and Chen (2002) provide evidence for such a correlation asymmetry in the US stock market. See also Ang et al. (2006) and Hong et al. (2007).) The additive modeling of basis risk is neither consistent with the log-log model nor the standard approach to futures valuation nor can it capture asymmetries in correlations. Hence, modeling basis risk in a multiplicative way seems more attractive.

Mahul (2002) proposes the first type of multiplicative basis risk and focuses on the characteristics of an optimal hedging portfolio that consists of futures and straddles. This paper takes a different route by explicitly deriving the optimal futures position and by also considering the reverse type of multiplicative dependence. ${ }^{2}$

For an unbiased futures market, the results are the following: Given the first type of dependence, positive prudence is a necessary and sufficient condition for underhedging; a full hedge is optimal under quadratic utility only. For the second type of dependence, non-negative prudence is a sufficient condition for underhedging. These results indicate that the nature of basis risk is essential for the optimal cross hedge. ${ }^{3}$

Ultimately, it is an empirical question whether basis risk is additive or multiplicative in a given cross hedging problem. We analyze the example of cross hedging jet fuel price risk using crude oil futures. Jet fuel price risk is important for airlines as jet fuel prices are very volatile and the exposure to this risk is large. However, derivatives on jet fuel are not being traded in larger volumes such that airlines have to resort to derivatives on related oil products such as crude oil. We focus on monthly jet fuel prices and onemonth NYMEX futures contracts on crude oil from 4/1990 to 8/ 2010 and show by means of a vector error correction (VEC) approach that the multiplicative specification describes the joint behavior of the price series better than the additive specification. We then derive the optimal cross hedging position and show that the difference to the position optimal under additive basis risk is economically significant. In sum, the case of jet fuel hedging demonstrates that the nature of basis risk matters for the optimal cross hedge.

The organization of the paper is as follows: Section 2 delineates the framework of analysis. Section 3 presents the two types of multiplicative dependence in detail and contrasts them to the additive types. Section 4 analyzes optimal futures hedging under multiplicative basis risk. Section 5 presents the data, the methodology and the results for an airline's optimal cross hedge of jet fuel price risk. Section 6 concludes. All proofs are in Appendix A.

\section{The basic model}

The analysis is based on the standard two-date expected utility hedging model: At date 0 , the risk-averse decision maker has a given exposure $Q$ to a price risk $\widetilde{P}^{4}$ At date 1 , quantity $Q$ is sold

\footnotetext{
${ }^{2}$ Considering non-linear instruments such as options is outside the scope of this paper. Hentschel and Kothari (2001) show that linear contracts such as forwards, futures and swaps seem to play a dominant role at least in corporate hedging.

${ }^{3}$ Focusing on background risk, Franke et al. (2006) show that multiplicatively combined risks lead to different risk taking if compared to additively combined risks.

${ }^{4}$ Henceforth, random variables have a tilde $(\sim)$ while their realizations do not. A $\operatorname{star}\left({ }^{*}\right)$ indicates an optimized level.
}

at the random future spot price $\widetilde{P}$. At date 0 , the decision maker can sell an amount $X$ in an infinitely divisible futures contract at the given futures price $f$ and will unwind the futures position at date 1 at the random futures price $\widetilde{F}{ }^{5}$ Hence, final wealth is given by $\widetilde{W}=\widetilde{P} Q+(f-\widetilde{F}) X$. Preferences are summarized by a utility function $U(W)$ that is at least three times continuously differentiable and exhibits risk aversion, $U^{\prime}(W)>0, \quad U^{\prime \prime}(W)<0$. In addition, $\lim _{W \rightarrow 0} U^{\prime}(W) \rightarrow+\infty$ and $\lim _{W \rightarrow+\infty} U^{\prime}(W) \rightarrow 0$.

It seems reasonable to assume that privately held, owner-managed firms behave in a risk-averse manner. But even firms with well-diversified shareholders and separation of ownership and control tend to behave as if they were risk-averse. There is a large body of literature that supports this view using a variety of arguments including agency considerations (Stulz, 1984; DeMarzo and Duffie, 1995; Morellec and Smith, 2007), corporate taxes and costs of financial distress (Smith and Stulz, 1985; Graham and Smith, 1999; Graham and Rogers, 2002) as well as other capital market imperfections (Stulz, 1990; Froot et al., 1993). Brown and Toft (2002) consider a value-maximizing firm facing deadweight costs that are convex in the firm's profits, thereby concavifying the firm's objective function. Against this background, the results derived here are also valid for corporate risk management applications.

At date 0 , the decision maker's problem is to maximize expected utility, $\mathrm{E}[U(\widetilde{W})]$, by choosing a hedging position, $X$, in order to manage price risk. Since the utility function is concave and $U^{\prime}(W) \in(0, \infty)$, the first-order condition for the optimal futures position, $X^{*}$, is necessary and sufficient for a unique and interior optimum. It is given by

$$
\mathrm{E}\left[U^{\prime}\left(\widetilde{W}^{*}\right)(f-\widetilde{F})\right]=0 .
$$

In order to rule out any speculative position taking and to focus on the hedging role of futures contracts, we assume an unbiased futures market, $f=\mathrm{E}[\widetilde{F}]_{.}^{6}$ Consequently, the first-order condition reduces to $-\operatorname{cov}\left(U^{\prime}\left(\widetilde{W}^{*}\right), \widetilde{F}\right)=0$. In the case of backwardation or contango, $f \neq \mathrm{E}[\widetilde{F}]$, there will be speculative positions which could be easily incorporated into the model.

We assume that the decision maker cannot eliminate price risk entirely from final wealth as the capital market is incomplete in the sense that $\widetilde{P}$ and $\widetilde{F}$ are not perfectly correlated. There are at least three reasons for this incompleteness.

The first reason is a timing mismatch in futures markets: The futures position will have to be liquidated at date 1 but expires at some later date 2 . Whenever the timing of the decision maker's exposure does not fit into the maturity structure available in the futures market, there will be a timing mismatch. ${ }^{7,8}$

The second reason is that there is no futures contract available for the assets that establish the price risk exposure. Using index futures to hedge against price risks of individual portfolios is one example. Another example is that of an insurance company with exposure towards hurricane damages in the US. If the insurer hedges using futures on the hurricane index of the Chicago Mercantile Exchange, the cash flow from the futures contract will, in the case of a hurricane, not exactly match the claims from its customers as the index is calculated in a way that differs from the insurance company's portfolio of risks. ${ }^{9}$ A third example is commodity contracts where a closer look at the details of the con-

\footnotetext{
${ }^{5}$ Of course, $\widetilde{P}$ and $\widetilde{F}$ are assumed to have positive realizations only, $P>0, F>0$.

${ }^{6}$ In a closely related forward market setting, Benninga and Oosterhof (2004) show that the representative agent does not necessarily have to be risk neutral in order to ensure that the forward market is unbiased.

7 In forward markets, a related argument can be made as forward markets have a small number of liquid maturity dates only.

${ }^{8}$ For the sake of simplicity of the model, we refrain from explicitly considering date 2 in the framework of a multiperiod model. In an multiperiod framework with additive utility, the results remain the same.

${ }^{9}$ See SwissRe (2009).
} 
tract often reveals that only a very limited number of qualities or grades of a commodity are actually used to calculate what is the underlying of the contract. ${ }^{10}$ If the exposure is in another grade, there is a capital market incompleteness although this incompleteness is far less pronounced than in the other two examples.

A third reason does not relate to futures contracts but to forward contracts. Default risk in forward contracts establishes another market incompleteness: If the counterparty defaults, the forward contract is ineffective at least for $f>F$ (for the short hedger), leaving the hedger exposed to price risk. ${ }^{11}$ It is worth noting that the model presented here is sufficiently flexible for the derivatives contract to be interpreted as a forward contract.

In the following, the basis is defined as the difference between the futures price $\widetilde{F}$ and the future spot price $\widetilde{P} \cdot{ }^{12}$ Since the futures contract does not perfectly match the decision maker's price risk, the basis is stochastic, hence there is basis risk in addition to price risk. Consequently, risk management has to rely on cross hedging. Whatever the futures position, final wealth is never deterministic if there is basis risk. In order to formalize basis risk, an additional random variable, denoted $\tilde{g}$ or $\tilde{\gamma}$, has to be incorporated into the model. This can be done either by assuming that the spot price is a function of the futures price and basis risk, $\widetilde{P}=p(\widetilde{F}, \tilde{\gamma})$, or by assuming that the futures price is a function of the spot price and basis risk, $\widetilde{F}=\phi(\widetilde{P}, \tilde{g}){ }^{13}$

\section{Additive versus multiplicative basis risk}

This section briefly reviews additive basis risk and presents two types of multiplicative basis risk as an alternative.

So far, the literature focused on additive relationships between basis risk and either $\widetilde{F}$ or $\widetilde{P}$. Building on Benninga et al. (1983), Lence (1995) considers

$\widetilde{P}=p(\widetilde{F}, \tilde{\gamma})=\kappa \widetilde{F}+\omega(\tilde{\gamma})$

for an arbitrary constant $\kappa$ and some arbitrary function $\omega(\cdot)$ with $\mathrm{E}[\omega(\tilde{\gamma})]=0$. He shows that conditional independence of $\widetilde{F}$ from $\tilde{\gamma}$ is necessary and sufficient for the optimality of a full hedge in an unbiased futures market, $X^{*}=\kappa Q .{ }^{14}$ This full hedge is optimal for any risk-averse decision maker irrespective of the size of basis risk, i.e. of the volatility of $\omega(\tilde{\gamma})$.

The reverse relationship (A.2) is given by

$$
\widetilde{F}=\phi(\widetilde{P}, \tilde{g})=k \widetilde{P}+w(\tilde{g})
$$

where $\widetilde{P}$ and $\tilde{g}$ are stochastically independent and $w(\cdot)$ is a linear function. ${ }^{15}$ Briys et al. (1993), Broll et al. (1995) and others show that an underhedging position is optimal for all risk averters, $X^{*}<Q / k$ for $k>0$. Under both additive relationships, basis risk is independent of the level of $\widetilde{F}$ and $\widetilde{P}$.

As an alternative, this paper proposes two multiplicative relationships, labeled (M.1) and (M.2):

\footnotetext{
${ }^{10}$ For example, only three grades of soybeans (corn) are deliverable under the soybean (corn) futures contract at the Chicago Mercantile Exchange.

11 Korn (2010) analyzes forward hedging with counterparty default risk. Doherty and Schlesinger (1990) focus on an insurance purchasing problem where the insurer might default.

${ }^{12}$ This definition of the basis differs from the more widely used definition in which the basis is the difference between a commodity's current spot price and its current futures price. Basis risk under this alternative definition relates to a situation in which this difference is risky. (This is also known as spread risk.) Using our definition, there is no need to model the current spot price of the underlying of the futures contract.

13 Both cases have to be considered separately since $p(\cdot)$ and $\phi(\cdot)$ are not necessarily invertible.

${ }^{14} \tilde{x}$ is said to be conditionally independent of $\tilde{y}$ if $\mathrm{E}[\tilde{x} \mid y]=\mathrm{E}[\tilde{x}] \forall y$. Under mild regularity conditions, this is equivalent to $\operatorname{cov}(\tilde{x}, h(\tilde{y}))=0$ for all functions $h(\cdot)$. See Ingersoll (1987, p. 15).

15 (A.2) is not exactly the reverse relationship of (A.1) because independence is stronger than conditional independence. In addition, the linearity assumption imposed on $w(\cdot)$ is not needed for $\omega(\cdot)$.
}

$\widetilde{P}=\beta \widetilde{F} \tilde{\theta}$,

where $\tilde{\theta}$ is conditionally independent of $\widetilde{F}$. $\tilde{\theta}$ has support in the interval $[\underline{\theta}, \bar{\theta}]$ with $0<\underline{\theta}<1<\bar{\theta}<\infty$ and $\mathrm{E}[\tilde{\theta}]=1$. The support of $\widetilde{F}$ is a subset of $[\underline{F}, \bar{F}]$ with $0<\underline{F}<\bar{F}<\infty$. Without loss of generality, $\beta>0$. These assumptions imply $P>0$ and $\mathrm{E}[\widetilde{P}]=\beta \mathrm{E}[\widetilde{F}]$. Under (M.1), the spot price $\widetilde{P}$ is a multiplicative combination of basis risk $\tilde{\theta}$ and the futures price $\widetilde{F}$. Hence, basis risk from $\tilde{\theta}$ is proportional to $F$ under (M.1).

Next, consider (M.2) as defined by

$\widetilde{F}=b \widetilde{P} \tilde{\vartheta}$

where $\tilde{\vartheta}$ and $\widetilde{P}$ are stochastically independent. The support of $\tilde{\vartheta}$ is a subset of $[\underline{\vartheta}, \bar{\vartheta}]$ with $0<\underline{\vartheta}<1<\bar{\vartheta}<\infty$ and $\mathrm{E}[\tilde{\vartheta}]=1$. The support of $\widetilde{P}$ is contained in $[\underline{P}, \bar{P}]$ with $0<\underline{P}<\bar{P}<\infty$. Again for simplicity, $b>0 .{ }^{16} F>0$ and $\mathrm{E}[\widetilde{F}]=b \mathrm{E}[\widetilde{P}]$ follow. Under (M.2), the futures price $\widetilde{F}$ is a multiplicative combination of basis risk $\tilde{\vartheta}$ and the spot price $\widetilde{P}$. Under (M.2), basis risk arises from $\tilde{\vartheta}$ and is proportional to $P$.

There are two important technical remarks to be made here: Firstly, (M.1) cannot be derived from (M.2) and vice versa. $\tilde{\theta}$ captures basis risk under (M.1) and is conditionally independent of $\widetilde{F}$ such that it cannot be independent of $\widetilde{P}$ at the same time as required under (M.2). The same applies to (M.2) where $\tilde{\vartheta}$ is independent of $\widetilde{P}$ so that it cannot be conditionally independent of $\widetilde{F}$ as (M.1) requires. Secondly, the model is very flexible since the (marginal) distributions of $\widetilde{F}$ and $\widetilde{P}$ do not have to be restricted for as long as their difference satisfies (M.1) or (M.2). The same applies to the distributions of $\tilde{\theta}$ and $\tilde{\vartheta}$.

Multiplicative basis risk is more attractive than additive basis risk in at least two respects. Firstly, (M.1) is closely related to the $\log -\log$ model which is widely used in empirical studies on the relationship between the spot price $\widetilde{P}$ and the futures price $\tilde{F}{ }^{17}$ In the $\log -\log$ model, it is assumed that $\ln (\widetilde{P})=c+\ln (\widetilde{F})+\tilde{\epsilon}$ where $\widetilde{F}$ and $\tilde{\epsilon}$ are stochastically independent and $\mathrm{E}[\tilde{\epsilon}]=0$. Redefining $\ln (\beta)+\mathrm{E}[\ln \tilde{\theta}]=c$ and $\ln \tilde{\theta}-\mathrm{E}[\ln \tilde{\theta}]=\tilde{\epsilon}$ and taking the natural logarithm of (M.1) yields $\ln (\widetilde{P})=\ln (\beta)+\ln (\widetilde{F})+\ln (\tilde{\theta})=c+\ln (\widetilde{F})+\tilde{\epsilon}$. This shows that (M.1) is in line with the log-log model whereas the respective additive relationship, $\widetilde{P}=\kappa \widetilde{F}+\omega(\tilde{\gamma})$, is not.

Secondly, (M.2) is consistent with the standard approach to forward valuation. ${ }^{18}$ This approach employs a simple no arbitrage argument to suggest that, at date 1 , the forward price is given by $F=P e^{(r-\xi)}$ for a forward contract expiring at some later date 2 . In this relationship, $r$ denotes the risk-free interest rate between dates 1 and $2, \xi$ denotes either the convenience yield (for a commodity contract) or the dividend yield (for a financial contract) between these dates. Now, assume that this standard valuation approach is valid at date 1 . From the perspective of date 0 , neither $P$ nor $r$ nor $\xi$ are known with certainty. Hence, they have to be treated as random variables such that the valuation relation becomes $\widetilde{F}=\widetilde{P} e^{(\tilde{r}-\tilde{\xi})}$. Setting $b=\mathrm{E}\left[e^{(\tilde{r}-\tilde{\xi})}\right]$ and $\tilde{\vartheta}=e^{(\tilde{r}-\tilde{\xi})} / b$ demonstrates that the standard approach to forward pricing is fully compatible with (M.2). ${ }^{19}$ This is a clear advantage of (M.2) over the corresponding additive relationship, $\widetilde{F}=k \widetilde{P}+w(\tilde{g})$, which is obviously not consistent with the standard valuation approach.

Multiplicative basis risk is capable of capturing the effects of asymmetric correlations between prices that depend on the direction of the price change. As Ang and Chen (2002) show for the US stock market, correlations between individual stocks and

\footnotetext{
${ }^{16}$ All results can also be derived for $\beta<0$ and $b<0$, with some obvious modifications. Adding a constant term to the RHS of (M.1) or (M.2) does not change the results either.

17 See the surveys by Chow et al. (2000) and Lien and Tse (2002).

18 See Working (1949).

19 Notice that the joint distribution of $\tilde{r}$ and $\tilde{\xi}$ does not have to be restricted since $e^{(r-\xi)}$ is always positive so that $\vartheta>0$ as is required by (M.2).
} 
the aggregate market have been larger in market downturns than in market upturns. (Bekaert and $\mathrm{Wu}(2000)$ point to a related phenomenon in the Japanese equity market. See also Ang et al. (2006) and Hong et al. (2007).) If an investor uses futures contracts on a market index to hedge an individual equity portfolio, this has the following implications: If equity prices decline, the (conditional) correlation between the portfolio value and the futures price is larger and, therefore, basis risk is smaller. But if (conditional) correlation decreases when equity prices rise, basis risk grows as well. This is perfectly in line with assumptions (M.1) and (M.2) as basis risk is proportional to the price level. In contrast, additive basis risk cannot capture the effects of such correlation asymmetries.

Whether an additive or a multiplicative type of basis risk is more appropriate in a given hedging problem has to be determined empirically. However, from an economic point of view, the nature of price changes in the economy might provide an indication of whether basis risk is multiplicative or additive. For example, consider the case of a commodity hedge in which the spot price $\widetilde{P}$ and the price of the underlying of the futures contract differ in their expected real production costs by a constant amount. ${ }^{20}$ If the general price level in the economy under consideration is almost stable, the difference between the two prices should reflect the monetary equivalent of the difference in real production costs plus any deviation from the expected level. The price difference will also capture any erratic change that is not related to the real production costs difference. In such a case, additive basis risk can be expected to be superior to its multiplicative counterpart. If, in contrast, the general price level in the economy is highly volatile, the monetary equivalent of the (constant) real production costs as such varies positively with the general price level. In this case, both prices as well as their (nominal) difference vary positively with the price level, making multiplicative basis risk the more intuitively appealing assumption.

In Section 5, we provide an example by analyzing optimal jet fuel hedges using crude oil futures contracts.

\section{Optimal cross hedging under multiplicative basis risk}

This section presents the optimal futures positions under assumptions (M.1) and (M.2). We summarize the main results in two propositions.

Under (M.1), price risk $\widetilde{P}$ can be interpreted as a bundle of tradable futures price risk $\widetilde{F}$ and untradable basis risk $\tilde{\theta}$. Final wealth under (M.1) is given by

$\widetilde{W}=\tilde{\theta} \widetilde{F} \beta Q+\psi(\widetilde{F}, X)$,

where $\psi(\widetilde{F}, X)=(f-\widetilde{F}) X$ does not depend on $\tilde{\theta}$. The first summand in (2) shows that the decision maker's exposure to untradable basis risk $\tilde{\theta}$ is independent of the futures position $X$. However, the multiplicative relationship between $\tilde{\theta}$ and $\widetilde{F}$ establishes an indirect link through $\psi(\widetilde{F}, X) .{ }^{21}$ Therefore, basis risk $\tilde{\theta}$ will generally affect the optimal futures position even though it is only indirectly related to it.

Before presenting the main result of the paper in Proposition 1, it is worth taking a closer look at the result derived by Lence (1995). Holthausen (1979) shows that full hedging is optimal if there is no basis risk and the futures market is unbiased. ${ }^{22}$ If basis risk is additive

\footnotetext{
20 See Adam-Müller and Wong (2003) for a related argument in the context of futures hedging under delivery risk.

21 This multiplicative combination of $\tilde{\theta}$ and $\widetilde{F}$ is the reason why basis risk is not identical to an additive background risk. For the case of an additive independent background risk, Briys et al. (1993) show that full hedging in an unbiased forward market is optimal for any risk-averse decision maker.

22 Benninga and Oosterhof (2004) show that this holds even if the decision maker's individual valuation of the forward contract differs from the market's valuation.
}

as in Lence's (1995) model, full hedging is still optimal for all riskaverse decision makers. Therefore, in his framework, the size of the basis risk or whether it exists at all has no impact on the optimal decision. The reason for this somewhat counterintuitive result is that, by assumption, price risk $\widetilde{P}$ is decomposed into a tradable part $\kappa \widetilde{F}$ and an independent, non-tradable part that captures basis risk, $\widetilde{P}=\kappa \widetilde{F}+\omega(\tilde{\gamma})$. Since there is neither a direct nor an indirect connection between basis risk and the futures position, the decision maker can only use the futures market to entirely sell the tradable part of the $\widetilde{P}$-risk which is the risk from $\widetilde{F}$. This particular assumption on the additive nature of basis risk is unsatisfactory because the economic conflict between managing price risk arising from $\widetilde{P}$ and, in doing so, generating additional risk in the form of basis risk is defined away in the first place. Hence, the economic conflict is not accounted for under this type of additive basis risk. It is therefore not surprising that the optimal decision ignores basis risk.

In sharp contrast, Proposition 1 clearly shows that there is such a conflict under (M.1). More importantly, it also shows how the decision maker's preferences determine the optimal decision against the background of this conflict as the optimal futures position depends on the decision maker's prudence (Kimball, 1990).

Proposition 1. Suppose that the futures market is unbiased and that (M.1) holds. The optimal futures position is a short hedge, $X^{*}>0$. An underhedging position, $X^{*}<\beta Q$ is optimal if and only if the decision maker is prudent, $U^{\prime \prime}(\cdot)>0 .^{23}$

All risk-averse decision makers optimally sell at least a fraction of their exposure to $\widetilde{P}$ in the futures market such that $X^{*}>0$. More importantly, a prudent decision maker optimally chooses an underhedging position. The futures position that minimizes the variance of $\widetilde{W}$ is the full hedge, $X^{v m, 1}=\beta Q .^{24} \mathrm{~A}$ full hedge is optimal only under quadratic utility.

In order to see the intuition behind Proposition 1, rewrite the first-order condition for $X^{*}$ as $\mathrm{E}\left\{\mathrm{E}\left[U^{\prime}\left(\tilde{\theta} F \beta Q+\psi\left(F, X^{*}\right)\right) \mid F\right](f-\widetilde{F})\right\}$ $=0$, applying the law of iterated expectations. Using a Taylor expansion of $U^{\prime}(\cdot)$ around $\psi(F, X)$, expected marginal utility for a given $F$ and a small $\tilde{\theta}$-risk can be written as

$$
\begin{aligned}
\mathrm{E}\left[U^{\prime}(\tilde{\theta} F \beta Q+\psi(F, X)) \mid F\right]= & U^{\prime}(F \beta Q+\psi(F, X))+\operatorname{var}(\tilde{\theta}) \\
& \times \frac{(F \beta Q)^{2}}{2} U^{\prime \prime \prime}(F \beta Q+\psi(F, X)) .
\end{aligned}
$$

Since marginal utility is decisive for hedging, the second term on the RHS of (3) indicates that the impact of basis risk $\tilde{\theta}$ on the optimal futures position $X^{*}$ depends on $F$ and on $U^{\prime \prime}(\cdot)$. This dependence of $X^{*}$ on $F$ establishes the indirect link between basis risk and the optimal futures position. If and only if utility is quadratic, basis risk is ignored such that full hedging is optimal. Whenever marginal utility is not linear, basis risk is taken into account such that it affects the optimal futures position.

Proposition 1 shows how non-linear marginal utility determines the optimal decision: Positive prudence, $U^{\prime \prime \prime}(\cdot)>0$, is a necessary and sufficient condition for the optimality of an underhedging position. Positive prudence is a commonly accepted property of utility functions and has become an integral part of the literature on behavior under uncertainty as based on the expected utility paradigm. ${ }^{25}$ Essentially, positive prudence implies that the decision maker has a precautionary incentive to avoid particularly low realizations of final

\footnotetext{
${ }^{23}$ As shown in Appendix A, $X^{*}>[=] \beta Q$ if and only if $U^{\prime \prime}(\cdot)<[=] 0$.

24 Conditional independence of $\tilde{\theta}$ from $\widetilde{F}$ together with $\mathrm{E}[\tilde{\theta}]=1$ implies $\operatorname{cov}(\widetilde{F}, \tilde{\theta} \widetilde{F})=\operatorname{var}(\widetilde{F})$ such that $\operatorname{var}(\widetilde{W})=\left(X^{2}-2 \beta Q X\right) \operatorname{var}(\widetilde{F})+(\beta Q)^{2} \operatorname{var}(\tilde{\theta} \widetilde{F}) \cdot X^{v m, 1}=\beta Q$ directly follows.

25 Positive prudence is a necessary condition for decreasing absolute risk aversion. Further arguments in favor of positive prudence can be found in Gollier (2001, chapter 16), among others.
} 
wealth. It also implies that the motivation to increase final wealth in such states is stronger than under quadratic utility. ${ }^{26}$

In order to see how prudence affects the optimal decision, it is useful to start at the full hedge position, $X^{v m, 1}=\beta Q$. At $X^{v m, 1}$, states with very low $W$ are characterized by a very low realization of $\tilde{\theta}$ together with a very high realization of $\widetilde{F}$ as follows from $\widetilde{W}\left(X=X^{v m, 1}\right)=\tilde{\theta} \widetilde{F} \beta Q+(f-\widetilde{F}) X^{v m, 1}=\widetilde{F} X^{v m, 1}(\tilde{\theta}-1)+f X^{v m, 1}$. As (2) indicates, generating additional final wealth in states with high $F$ requires selling less futures contracts since this is the only possibility to increase $\partial W / \partial F$. Thus, the optimal futures position of a prudent decision maker is equivalent to an underhedge, $X^{*}<\beta Q=X^{v m, 1}$

Kimball (1990) shows that prudence plays a crucial role in the presence of an additive background risk. Proposition 1 shows that the decision maker's prudence is also essential in the presence of a multiplicative basis risk. Benninga et al. (1985) show that prudence is also important if there is tradable price risk and independent, untradable quantity risk, but no basis risk. ${ }^{27}$ Lence (1995) mentions briefly that the optimal hedge ratio in the log-log model depends on the utility function but he does not specify the dependence. Proposition 1 does not only confirm his statement but also shows exactly how the optimal futures position depends on the decision maker's preferences.

Now, consider (M.2). Under (M.2), tradable futures price risk $\widetilde{F}$ is like a package of price risk $\widetilde{P}$ and basis risk $\tilde{\vartheta}$. While the exposure to $\tilde{P}$ is exogenously given by $Q$, the exposure to the package that forms $\widetilde{F}$ is endogenously determined via the futures position $X$. In other words, if the decision maker seeks protection against fluctuations in $\widetilde{P}$ by trading $\widetilde{F}$, this creates exposure to basis risk $\tilde{\vartheta}$. Under (M.2), final wealth can be written as

$\widetilde{W}=\widetilde{P}(Q-b X)+b X \widetilde{P}(1-\tilde{\vartheta})+f X$.

The second term on the RHS of (4) shows that basis risk $\tilde{\vartheta}$ enters final wealth only in multiplicative combination with $\widetilde{P}$ and $X$. There is no basis risk if there is no futures position, $X=0$. At full hedging, $X=Q / b$, the isolated effect of price risk $\widetilde{P}$ on $\widetilde{W}$ as represented by the first term on the RHS of (4) is eliminated. However, any futures position exposes final wealth to basis risk $\tilde{\vartheta}$. Hence, there is a conflict between reducing price risk $\widetilde{P}$ and avoiding basis risk $\tilde{\vartheta}$ : The first term on the RHS of (4) favors a full hedging position, the second a futures position of zero. The next result characterizes the optimal futures position:

Proposition 2. Suppose that the futures market is unbiased and that (M.2) holds.

(a) The optimal futures position is a short hedge, $X^{*}>0$.

(b) If $U^{\prime \prime \prime}(\cdot) \geqslant 0$, the optimal futures position is an underhedge, $X^{*}<Q / b$

Part (a) of Proposition 2 shows that all risk-averse decision makers will optimally hedge at least part of the price risk $\widetilde{P}$ by

\footnotetext{
$\overline{26}$ Brown and Toft (2002) argue that a value-maximizing firm hedges because it might face costly states of nature where profits are very low. In a similar spirit, a prudent decision maker focuses on states with very low final wealth.

27 In the absence of basis risk, $\widetilde{P}=\beta \widetilde{F}$. To connect the model analyzed here to the Benninga et al. (1985) model, define a random variable $\tilde{n}$, independent of $\widetilde{P}$ with $\mathrm{E}[\tilde{n}]=1$ and $n \geqslant 0$. Then, the exposure is given by $Q \tilde{n}$ and final wealth becomes $\widetilde{W}=\tilde{n} \beta \widetilde{F} Q+\psi(\widetilde{F}, X)$ where $\psi(\widetilde{F}, X)$ is defined as in (2). The first summand here, $\tilde{n} \beta \widetilde{F} Q$, captures quantity risk whereas the first summand in (2) captures basis risk. Apart from this, the problems are almost isomorphic. This explains why Proposition 1 is in line with the result derived by Benninga et al. (1985). Dependent price and quantity risk is analyzed by Brown and Toft (2002) for a value-maximizing firm and by Wong (2003) in an expected utility framework, but neither model incorporates basis risk.
}

choosing a positive futures position, $X^{*}>0$. This causes final wealth to depend on basis risk $\tilde{\vartheta}$ as well. The decision maker enjoys a gain from diversification: $X^{*}>0$ is the same as selling part of one risk $(\widetilde{P})$ and acquiring another risk $(\tilde{\vartheta} \widetilde{P})$ which is imperfectly correlated with the first.

Part (b) of Proposition 2 states that non-negative prudence is a sufficient condition for underhedging under (M.2). To see why, consider a prudent decision maker who starts at full hedging. Final wealth, expressed in terms of tradable futures price risk $\widetilde{F}$ and untradable basis risk $\tilde{\vartheta}$, is then given by

$\widetilde{W}(X=Q / b)=\frac{Q}{b}\left[f+\left(\frac{1-\tilde{\vartheta}}{\tilde{\vartheta}}\right) \widetilde{F}\right]$.

Since $b, F, Q>0$ in all states, final wealth is low when both the realization of $\tilde{\vartheta}$ and $\widetilde{F}$ are high at the same time. Positive prudence creates a strong motive to generate additional wealth in these unfavorable states. Generating wealth in states with high $F$ requires a reduction of the futures position. Hence, underhedging is optimal.

The variance-minimizing position under (M.2) is given by ${ }^{28}$

$X^{v m, 2}=\frac{Q}{b}\left(\frac{\operatorname{var}(\widetilde{P})}{E\left[\widetilde{P}^{2}\right] \operatorname{var}(\tilde{\vartheta})+\operatorname{var}(\widetilde{P})}\right)=\frac{Q}{b} K$,

where $K$ is a positive constant below unity. Hence, the varianceminimizing futures position is always an underhedging position as implicitly claimed in part (b) of Proposition $2 .{ }^{29} \mathrm{~K}$ captures the relative size of price risk and independent basis risk. Since $K$ decreases in $\operatorname{var}(\tilde{\vartheta})$ and increases in $\operatorname{var}(\widetilde{P}), X^{v m, 2}$ exhibits intuitively plausible comparative statics. ${ }^{30}$

The optimal hedging position for a prudent decision maker under (M.1) and under (M.2) is an underhedging position. When the model is applied to corporate risk management, its predictions are qualitatively consistent with some stylized facts about corporate hedging as presented by Bodnar et al. (1998). Hence, basis risk offers an explanation for why firms on average only hedge a fraction of their perceived exposures. Other explanations are based on 'selective hedging' (Stulz, 1984), the existence of independent untradable quantity risk (Benninga et al., 1985) and correlation between price risk and quantity risk (Brown and Toft, 2002).

\section{An application: Cross hedging jet fuel price risk}

In this section, we compare the optimal futures positions under the additive specification (A.1) and under the multiplicative specification (M.1). As the optimal futures position is always a full hedge under (A.1), this case provides an almost natural benchmark for comparison. As an illustration, we consider the case of an airline's optimal management of jet fuel price risk.

\footnotetext{
${ }^{28}$ Since $\operatorname{var}((1-\tilde{\vartheta}) \tilde{P})=\mathrm{E}\left[\widetilde{P}^{2}\right] \operatorname{var}(\tilde{\vartheta})$ and $\operatorname{cov}(\widetilde{P},(1-\tilde{\vartheta}) \tilde{P})=0$, it is straightforward to show that $\operatorname{var}(\widetilde{W})=(Q-b X)^{2} \operatorname{var}(\widetilde{P})+(b X)^{2} \mathrm{E}\left[\widetilde{P}^{2}\right] \operatorname{var}(\tilde{\vartheta})$. (6) follows directly.

${ }^{29}$ Under (M.1), a prudent decision maker's optimal futures position is always below the variance-minimizing position $X^{v m, 1}=\beta Q$. Under (M.2), a similar statement cannot be derived.

30 The intuitive argument for why Proposition 2 only provides a sufficient condition for underhedging is as follows: $X^{v m, 2}$ is optimal if and only if prudence is zero (quadratic utility) as the futures market is unbiased. Consider a small change in preferences such that the decision maker exhibits a small degree of negative prudence. This creates an incentive to increase the futures position. As $X^{v m, 2}$ is an underhedging position, the optimal futures position will remain an underhedge. For a given distribution of $\tilde{\vartheta}$ and $\widetilde{P}$, the optimal futures position is likely to increase as prudence becomes more negative. However, one will have to specify the joint distribution and/or the utility function in order to derive a rigorous formal argument along these lines.
} 
Table 1

Jet fuel costs of nine large passenger airlines in 2009.

\begin{tabular}{|c|c|c|c|}
\hline \multirow[t]{2}{*}{ Airline name } & \multirow{2}{*}{$\begin{array}{l}\text { Revenue passenger } \\
\text { miles }(\mathrm{m})\end{array}$} & \multicolumn{2}{|c|}{ Jet fuel costs } \\
\hline & & $\begin{array}{l}\text { in } \\
\text { USD } \\
(\mathrm{m})\end{array}$ & $\begin{array}{l}\text { in \% of total } \\
\text { operating } \\
\text { expenses (\%) }\end{array}$ \\
\hline Delta Air Lines & 188,943 & 8,291 & 29.2 \\
\hline Air France-KLM ${ }^{\mathrm{a}, \mathrm{b}}$ & 125,800 & 6,678 & 35.7 \\
\hline American Airlines & 122,418 & 5,553 & 26.5 \\
\hline United Airlines & 100,475 & 3,405 & 20.6 \\
\hline Lufthansa $^{\mathrm{b}}$ & 99,821 & 4,714 & 18.7 \\
\hline Continental Airlines & 89,136 & 3,317 & 26.1 \\
\hline Southwest Airlines & 74,457 & 3,044 & 30.2 \\
\hline British Airways ${ }^{\mathrm{a}, \mathrm{b}}$ & 68,880 & 3,785 & 28.8 \\
\hline Singapore Airlines ${ }^{\mathrm{a}, \mathrm{b}}$ & 51,501 & 2,939 & 33.2 \\
\hline
\end{tabular}

Jet fuel costs amount to roughly $25-30 \%$ of an airline's operative expenses (see Table 1) such that the exposure to jet fuel price risk is high. As the price of jet fuel is highly volatile, this establishes a significant risk for many airlines. Trading volumes in jet fuel derivatives are small. ${ }^{31}$ Therefore, airlines have to resort to cross hedging by using contracts on other oil products such as crude oil.

We analyze cross hedging jet fuel price risk with one-month NYMEX crude oil futures contracts on West Texas Intermediate (WTI) crude oil. In particular, we investigate how these futures contracts can be optimally used to hedge against the risk from jet fuel prices for delivery at New York harbor. The hedging horizon is one month. All data was downloaded from the US Energy Information Administration webpage. ${ }^{32}$ Fig. 1 depicts both logarithmic prices series, ranging from $4 / 1990$ to $8 / 2010$ and containing 245 monthly observations.

In subsection 5.1, we show that the multiplicative specification of basis risk according to (M.1) fits the data better than the additive specification (A.1) by means of a vector error correction (VEC) approach. In subsection 5.2, we derive the optimal hedge ratios.

\subsection{Jet fuel price risk and the nature of basis risk}

It is obvious from Fig. 1 that both price series are integrated. The Johansen test for cointegration ${ }^{33}$ reveals that both series are actually cointegrated. Hence, both (A.1) and (M.1) have to be interpreted as cointegrating equations such that the validity as well as the explanatory power of the additive and the multiplicative model can be tested within a VEC modeling framework.

The corresponding cointegrating regression equation for (A.1) is given by

$P_{t}=\kappa F_{t}+\gamma_{t} \quad$ with $t=1, \ldots, T$

where $P_{t}$ denotes the logarithmic jet fuel spot price, $F_{t}$ the corresponding logarithmic one-month crude oil futures price at time $t$ and $\gamma_{t}$ denotes a zero mean error term. For the multiplicative case we consider

$P_{t}=\beta F_{t} \theta_{t} \quad$ with $t=1, \ldots, T$

where $\theta_{t}$ denotes a unit mean error term.

\footnotetext{
31 To the best of our knowledge, the only exchange-traded jet fuel contract is traded at the Tokyo Commodities Exchange. However, its trading volume is low and has declined significantly in recent years, see www.tocom.or.jp.

32 www.eia.doe.gov.

33 The Johansen trace test results are as follows: For the $H_{0}$ that no (at most 1 ) cointegration relationship exists, the test statistic is $32.7986(0.9604)$ with a $p$-value of 0.0000 (0.3271).
}

To formally test the additive specification against the multiplicative one we artificially nest both cointegrating equations into the following VEC model ${ }^{34}$ :

$$
\left(\begin{array}{c}
\Delta P_{t} \\
\Delta F_{t}
\end{array}\right)=\mu+\alpha \gamma_{t-1}+(1-\alpha) \delta\left(\theta_{t-1}-1\right)+\phi_{1}\left(\begin{array}{c}
\Delta P_{t-1} \\
\Delta F_{t-1}
\end{array}\right)+\ldots+\phi_{p}\left(\begin{array}{c}
\Delta P_{t-p} \\
\Delta F_{t-p}
\end{array}\right)+u_{t}
$$

It turns out that $p=1$ already provides a satisfactory fit in terms of the bivariate LB test for absence of residual serial correlation. Hence, we stick to this specification. The parameter vector $\alpha$ can now be tested by a Wald test to have zero components in which case the multiplicative cointegrating equation would clearly rule out the additive one. Table 2 presents the estimation results of this nested VEC model and the corresponding Wald test.

With a $p$-value of about $75 \%$, the Wald test indicates that it is not possible to reject the null hypothesis of both components in $\alpha$ being equal to zero, which shows that the multiplicative basis risk specification is superior to its additive counterpart in modelling the true data generating process.

\subsection{Optimal cross hedging}

In this subsection, we calculate the optimal hedge ratios under (M.1) and (A.1), using monthly data ranging from 4/1990 to 8/2010 (245 monthly observations).

We assume that the one-month crude oil futures price $F_{t}$ is lognormally distributed with mean $\mu_{F, t}$ and variance $\sigma_{F, t}^{2}$. For the additive type of basis risk, we use the following specification

$P_{t}=\kappa F_{t}+\gamma_{t}$.

For simplicity, we assume that $\gamma_{t} \sim N\left(0, \sigma_{\gamma}^{2}\right)$. For the multiplicative type of basis risk, we use

$P_{t}=\beta F_{t} \theta_{t}$

and assume, again for simplicity, that $\theta_{t} \sim N\left(1, \sigma_{\theta}^{2}\right)$.

The parameters $\kappa$ and $\beta$ are estimated for each point in time $t$ by the expanding window regressions (C-A.1 $\left.1^{\prime}\right)$ and (C-M.1'), starting with an initial window of 58 months length in $1 / 1995 . \sigma_{\gamma}^{2}$ and $\sigma_{\theta}^{2}$ are calculated from the residual series of these regressions. $\sigma_{F, t}^{2}$ is calculated as the historical variance from all data prior to time $t$. In total, we obtain $t=1, \ldots, 188$ observations for each parameter. As the futures market is assumed to be unbiased, we have $f_{t}=\mu_{F, t}=\mathrm{E}_{t}\left[\widetilde{F}_{t+1}\right] .^{35}$ We re-estimate all parameters for every period with the intention to capture or mitigate effects of structural breaks in the system. Our estimation scheme therefore adapts itself to changes in the underlying data generating process, such as volatility or risk clustering (through $\sigma_{\gamma}^{2}$ and $\sigma_{\theta}^{2}$ ) and shifts in the price levels (through $\kappa$ and $\beta$ ).

We assume constant relative risk aversion of $z$ such that $U(W)=\frac{1}{1-z} W^{1-z}$. We then calculate optimal hedge ratios as defined by $X^{*} / Q$ for values of $z \in\{0.5,3,5,7\}$. In addition, we assume a hedging horizon of one month. On the 25th calendar day of each month, a position in the one-month futures contract is being taken and held for one month.

Omitting time indexes, final wealth under (C-A.1') is given by $\widetilde{W}=\widetilde{F}(\kappa Q-X)+\tilde{\gamma} Q+f X$. Hence, the decision problem is to choose $X$ so as to maximize

\footnotetext{
34 The results do not change qualitatively if an intercept is included in the cointegrating relationship. See also footnote 16 .

${ }^{35}$ It is not the purpose of this paper to test the unbiasedness of the NYMEX crude oil futures market. Without the unbiasedness assumption, there will be a speculative position in addition to the hedging position. In order to focus exclusively on the hedging position, any speculative position has to be ruled out.
} 


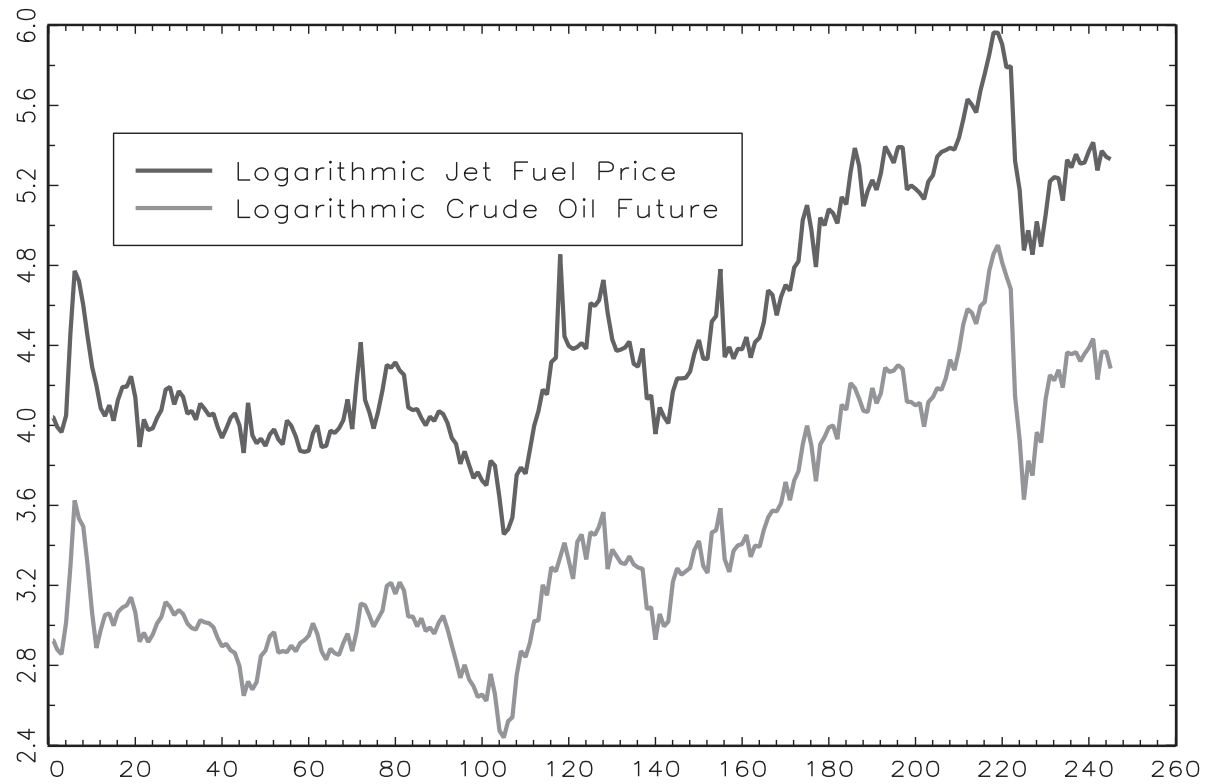

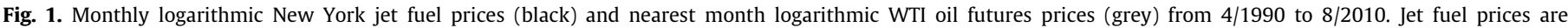
denominated in US cents per gallon, oil futures prices are denominated in USD per barrel.

Table 2

Estimation results of the nested VEC model.

\begin{tabular}{|c|c|c|}
\hline $\begin{array}{l}\text { Estimation Output } \\
\text { Parameters }\end{array}$ & $\begin{array}{l}\text { sted VEC System } \\
\text { Estimates }\end{array}$ & Std. deviations \\
\hline \multicolumn{3}{|c|}{ Cointegrating equations } \\
\hline$\kappa$ & 1.3027 & 0.0081 \\
\hline$\beta$ & 1.3426 & 0.0065 \\
\hline \multicolumn{3}{|l|}{ VEC } \\
\hline$\mu^{\prime}$ & $\left(\begin{array}{ll}-0.0171 & -0.0001\end{array}\right)$ & $\left(\begin{array}{ll}0.0291 & 0.0240\end{array}\right)$ \\
\hline$\phi_{1}$ & $\left(\begin{array}{ll}-0.2239 & 0.2499 \\
0.0402 & 0.0435\end{array}\right)$ & $\left(\begin{array}{ll}0.1018 & 0.1319 \\
0.1074 & 0.1217\end{array}\right)$ \\
\hline$\alpha^{\prime}$ & $\left(\begin{array}{ll}0.1742 & 0.0679\end{array}\right)$ & $\left(\begin{array}{ll}0.2496 & 0.2060\end{array}\right)$ \\
\hline$\delta^{\prime}$ & $\left(\begin{array}{ll}1.2504 & 0.2191\end{array}\right)$ & $\left(\begin{array}{ll}1.7260 & 1.0919\end{array}\right)$ \\
\hline Log-likelihood & & 514.0090 \\
\hline $\mathrm{BIC}$ & & -4.0044 \\
\hline LB (10) & & $43.2735(0.3334)$ \\
\hline LB (20) & & $85.0812(0.3278)$ \\
\hline Wald test $(\alpha=0)$ & & $0.5647(0.7540)$ \\
\hline
\end{tabular}

$\int_{0}^{\infty} \int_{0}^{\infty} \frac{1}{1-z}(F(\kappa Q-X)+\gamma Q+f X)^{1-z}$

$\times \frac{1}{\sigma_{F} F \sqrt{2 \pi}} \exp \frac{\frac{-\left(\ln (F)-\mu_{F}\right)^{2}}{2 \sigma_{F}^{2}}}{\sigma_{\gamma} \sqrt{2 \pi}} \exp ^{\frac{-\gamma^{2}}{2 \sigma_{\gamma}^{2}}} d F d \gamma$.

For multiplicative basis risk á la (C-M.1'), final wealth becomes $\widetilde{W}=(\tilde{\theta} \beta Q-X) \widetilde{F}+f X$ such that the decision problem is to choose $X$ to maximize

$$
\begin{aligned}
& \int_{0}^{\infty} \int_{0}^{\infty} \frac{1}{1-z}((\theta \beta Q-X) F+f X)^{1-z} \times \frac{1}{\sigma_{F} F \sqrt{2 \pi}} \exp \frac{-\left(\ln (F)-\mu_{F}\right)^{2}}{2 \sigma_{F}^{2}} \\
& \times \frac{1}{\sigma_{\theta} \sqrt{2 \pi}} \exp ^{\frac{-(\theta-1)^{2}}{2 \sigma_{\theta}^{2}}} d F d \theta .
\end{aligned}
$$

The optimal futures hedge ratios that solve (8) and (9) are shown in Fig. 2.

From Lence (1995), we know that $X^{*} / Q=\kappa$ under (A.1), independent of the degree of risk aversion and the volatility of basis risk. This result is independent of $\sigma_{F}, \sigma_{\gamma}$ and the degree of risk aversion.
The solid black line in Fig. 2 shows the optimal decisions under (A.1) for all levels of $z$. For the entire sample, the average $\kappa$ is 2.95645 ; the optimal hedge ratio varies only slightly in the range between 2.9 and 3.0.

Fig. 2 shows that the optimal hedge ratio depends on the nature of basis risk because the hedge ratios optimal under multiplicative basis risk are economically different from those under additive basis risk. Firstly, they are below the full hedge represented by the black line for the entire sample period. This is perfectly in line with Proposition 1. Secondly, the optimal hedge ratio under (M.1) depends on risk preferences. To be precise, the higher the degree of constant relative risk aversion $z$, the smaller the hedge ratio. This illustrates the intuitively plausible behavior that, given a certain level of basis risk, a more risk-averse decision maker will attach a higher weight to this basis risk in his decision such that a smaller futures position will be taken.

An interesting phenomenon can be observed at $t=60$. In March 1990 , there was a sudden strong increase in the price of jet fuel without a correspondingly large increase in the futures price of crude oil. For the purpose of interpretation, we can separate two effects. The first effect is an increase in the optimal hedge ratio which is simply due to an increase in $\kappa$ for (A.1) as well as an increase in $\beta$ for (M.1). The second effect relates to the volatility of basis risk. The second effect is only visible under (M.1) as the volatility of basis risk is ignored under (A.1). Given the price movements at $t=60$, the volatility of basis risk became significantly larger, making futures hedging less attractive. Taken in isolation, this effect reduces the optimal futures position. This second effect is larger the higher risk aversion. As Fig. 2 shows, the first effect slightly dominates the second for $z=0.5$. For higher levels of risk aversion, more weight is being attached to the second effect. For example, Fig. 2 shows a sharp drop in the optimal hedge ratio for $z=7$.

\section{Conclusions}

This paper analyzes optimal cross hedging with futures contracts. It focuses on two multiplicative relationships between basis risk on the one hand and the spot price or the futures price on the other. These relationships imply that basis risk is proportional to the level of the spot price or the futures price. 


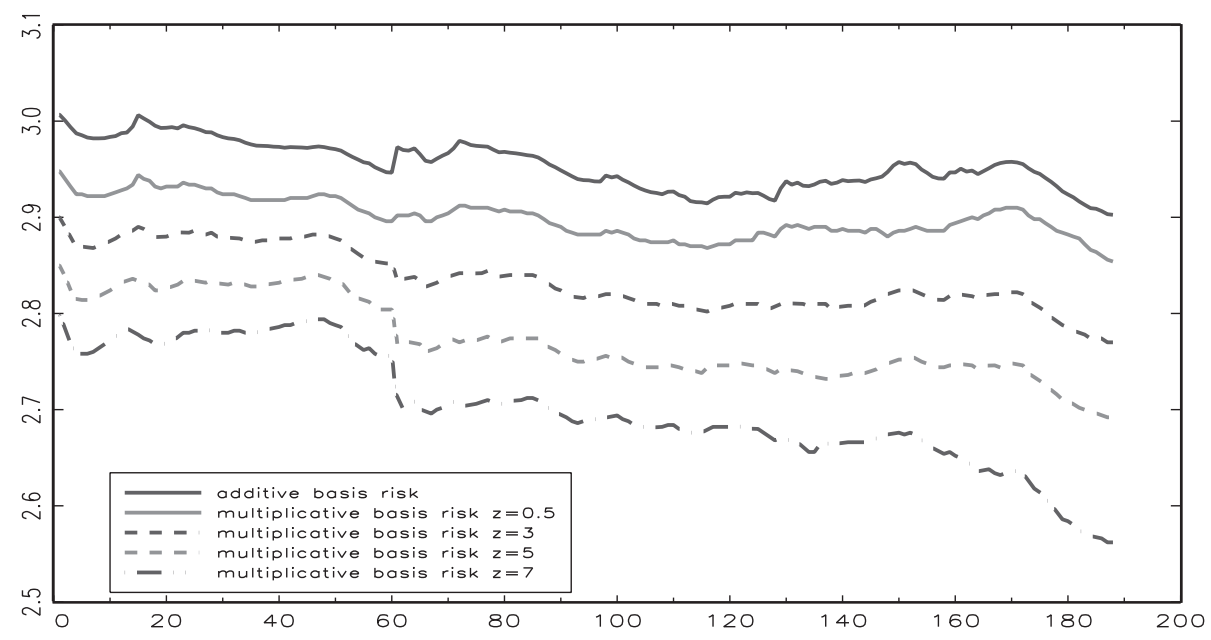

Fig. 2. Optimal hedge ratios, $X^{*} / Q$, for $z=0.5,3,5,7$.

The theoretical part of the paper shows that the optimal futures position under these multiplicative specifications crucially depends on the decision maker's prudence. If we combine basis risk in a multiplicative way with the futures price as under assumption (M.1), there is a direct link between the decision maker's prudence and the optimal futures position in an unbiased futures market: Underhedging is optimal if and only if prudence is positive. Under assumption (M.2) where basis risk is multiplicatively combined with the spot price, non-negative prudence is a sufficient condition for the optimality of an underhedging position. In sum, the analysis shows how, given multiplicative basis risk, the decision maker's preferences affect the quintessential tradeoff between reducing price risk and creating basis risk. ${ }^{36}$

In the empirical part of the paper, we analyze the problem of cross hedging jet fuel price risk with NYMEX crude oil futures. It turns out that the multiplicative specification of basis risk according to (M.1) is superior to its additive counterpart in describing the price series. We then show that hedge ratios optimal under (M.1) differ significantly from those optimal under (A.1). This demonstrates that the difference between multiplicative and additive basis risk is both statistically and economically significant. The implication for corporate hedging is that two steps are needed to calculate the optimal cross hedge: Firstly, one has to analyze the nature of basis risk in the given application. Using the result from the first step, the optimal hedge ratio can be derived in the second step.

\section{Acknowledgements}

We would like to thank Tomas Björk, Frank de Jong, Günter Franke, Olaf Korn, David Stolin, Stephen J. Taylor, Niklas Wagner, seminar participants at the Stockholm School of Economics and two anonymous referees for helpful comments and suggestions. Financial support from the British Council and the German Academic Exchange Service DAAD is gratefully acknowledged. All remaining errors are ours.

\footnotetext{
36 These results are closely related to two other standard decision problems under risk, one being a portfolio problem, the other being an insurance problem. In the analogous portfolio problem, the decision maker holds one risky asset and decides on how much of another asset to add to the existing position given that the other asset provides no excess return. In the analogous insurance problem, the insurer can only observe the realized loss with an error such that the indemnity does not perfectly match the loss. Gollier (1996) analyzes the nature of the optimal insurance contract in such an environment. He shows that a disappearing deductible is optimal if the policyholder is prudent and that this deductible equals zero if insurance is costless.
}

\section{Appendix A}

Proof of Proposition 1. The equivalence of $X^{*}<\beta Q$ to $U^{\prime \prime}(\cdot)>0$ is proven first. Unbiasedness and the law of iterated expectations imply that the first-order condition in (1) can be written as $-\operatorname{cov}\left(\mathrm{E}\left[U^{\prime}\left(\widetilde{W}^{*}\right) \mid F\right], \widetilde{F}\right)=0$ where $\widetilde{W}^{*}=\beta \widetilde{F} \tilde{\theta} Q+(f-\widetilde{F}) X^{*}$. Hence, $\mathrm{E}\left[U^{\prime}\left(\widetilde{W}^{*}\right) \mid F\right]$ is either a constant or it is decreasing in some interval of $F$ while increasing in some other interval of $F$. This requires

$$
\begin{aligned}
\frac{\partial \mathrm{E}\left[U^{\prime}(W) \mid F\right]}{\partial F}= & \mathrm{E}\left[U^{\prime \prime}(\widetilde{W})(\beta \tilde{\theta} Q-X) \mid F\right] \\
= & (\beta Q-X) \mathrm{E}\left[U^{\prime \prime}(\widetilde{W}) \mid F\right] \\
& +\beta Q \operatorname{cov}\left(U^{\prime \prime}(\widetilde{W}), \tilde{\theta} \mid F\right)
\end{aligned}
$$

to be equal to zero everywhere or to vary in sign. The derivation of (10) uses the fact that $\mathrm{E}[\tilde{\theta} \mid F]=\mathrm{E}[\tilde{\theta}]=1$ for all $F$. Since $\partial U^{\prime \prime}(W) / \partial \theta=$ $U^{\prime \prime \prime}(W) \beta F Q$ the fact that $\beta, Q, F>0$ implies $\operatorname{sgn} \operatorname{cov}\left(U^{\prime \prime}(\widetilde{W}), \tilde{\theta}\right)=$ sgn $U^{\prime \prime \prime}(\cdot)$ for all $F$.

The remainder of the proof is by contradiction. Suppose that $U^{\prime \prime \prime}(\cdot)>0$. Since $\beta, Q>0$, the second summand on the RHS of $(10)$ is positive. If $(\beta Q-X) \leqslant 0$, the first summand will be non-negative due to risk aversion such that there is no interval in which $\mathrm{E}\left[U^{\prime}(\widetilde{W}) \mid F\right]$ does not increase in $F$. Since this leads to a contradiction, the optimum must be characterized by $\left(\beta Q-X^{*}\right)>0$ for $U^{\prime \prime \prime}(\cdot)>0$. (Using the same argument, it is straightforward to show that $U^{\prime \prime \prime}(\cdot)<[=] 0$ is equivalent to $\left(\beta Q-X^{*}\right)<[=] 0$. $)$

In order to prove that $X^{*}>0$, irrespective of the sign of $U^{\prime \prime}(\cdot)$, evaluate (10) at $X=0$. As the first line of (10) shows, the expression is negative since $U^{\prime \prime}(\cdot)<0$ and $\beta, Q, \gamma>0$. Hence, the first-order condition in (1), evaluated at $X=0$, is positive. $X^{*}>0$ then follows from the concavity of the problem.

Proof of Proposition 2. Using the law of iterated expectations, the notation can be simplified by defining

$$
\begin{aligned}
& A(X)=\operatorname{cov}\left(U^{\prime \prime}(\widetilde{W}(X)), \tilde{\vartheta} \mid P\right)=\operatorname{cov}\left(\mathrm{E}\left[U^{\prime \prime}(\widetilde{W}(X)) \mid \vartheta\right], \tilde{\vartheta} \mid P\right), \\
& B(X)=\operatorname{cov}\left(U^{\prime}(\widetilde{W}(X)), \widetilde{P}\right)=\operatorname{cov}\left(\mathrm{E}\left[U^{\prime}(\widetilde{W}(X)) \mid P\right], \widetilde{P}\right),
\end{aligned}
$$




$$
C(X)=\operatorname{cov}\left(U^{\prime}(\widetilde{W}(X)) \widetilde{P}, \tilde{\vartheta}\right)=\operatorname{cov}\left(\mathrm{E}\left[U^{\prime}(\widetilde{W}(X)) \widetilde{P} \mid \vartheta\right], \tilde{\vartheta}\right) .
$$

Using (M.2), $\mathrm{E}[\tilde{\vartheta}]=1$ and $f=\mathrm{E}[\widetilde{F}]=b \mathrm{E}[\widetilde{P}]$ due to unbiasedness, one can rewrite the LHS of the first-order condition in (1) as

$$
\begin{aligned}
\mathrm{E}\left[U^{\prime}\left(\widetilde{W}\left(X^{*}\right)\right)(f-b \widetilde{P} \tilde{\vartheta})\right]= & \mathrm{E}\left[U^{\prime}\left(\widetilde{W}\left(X^{*}\right)\right)(f-b \widetilde{P})\right] \\
& +b \mathrm{E}\left[U^{\prime}\left(\widetilde{W}\left(X^{*}\right)\right) \widetilde{P}(1-\tilde{\vartheta})\right] \\
= & -b\left[B\left(X^{*}\right)+C\left(X^{*}\right)\right] .
\end{aligned}
$$

(1) and (14) imply $\left[B\left(X^{*}\right)+C\left(X^{*}\right)\right]=0$ since $b>0$.

The remainder of the proof is based on signing $A(X)$ to $C(X)$. In order to $\operatorname{sign} A(X)$, it is useful to derive

$\frac{\partial \mathrm{E}\left[U^{\prime \prime}(\widetilde{W}) \mid \vartheta, P\right]}{\partial \vartheta}=-b X \mathrm{E}\left[U^{\prime \prime \prime}(\widetilde{W}) P \mid \vartheta, P\right] \quad \forall \vartheta, P$.

Since $b, P>0,(15)$ implies sgn $A(X)=-\operatorname{sgn}\left\{X U^{\prime \prime \prime}(\cdot)\right\}$. To sign $B(X)$, notice that

$$
\begin{aligned}
\frac{\partial \mathrm{E}\left[U^{\prime}(\widetilde{W}) \mid P\right]}{\partial P} & =\mathrm{E}\left[U^{\prime \prime}(\widetilde{W})(Q-b X \tilde{\vartheta}) \mid P\right] \\
& =(Q-b X) \mathrm{E}\left[U^{\prime \prime}(\widetilde{W}) \mid P\right]-b X A(X) \quad \forall P
\end{aligned}
$$

since $\mathrm{E}[\tilde{\vartheta}]=1$. Signing $C(X)$ uses the fact that

$$
\frac{\partial \mathrm{E}\left[U^{\prime}(\widetilde{W}) \widetilde{P} \mid \vartheta\right]}{\partial \vartheta}=-b X \mathrm{E}\left[U^{\prime \prime}(\widetilde{W}) \widetilde{P}^{2} \mid \vartheta\right] \quad \forall \vartheta .
$$

Hence, $U^{\prime \prime}(W)<0$ and $b>0$ imply $\operatorname{sgn} C(X)=\operatorname{sgn} X$. Consider $X=0$. Then, (16) reduces to $\partial \mathrm{E}\left[U^{\prime}(\widetilde{W}) \mid P\right] / \partial P=\mathrm{E}\left[U^{\prime \prime}(\widetilde{W}) Q \mid P\right]$. Since $U^{\prime \prime}(\cdot)<0$ and $Q>0$, the conditional expectation is negative for all $P$ such that $B(0)<0$. In addition, $C(0)=0$. Hence, (14) is positive if evaluated at $X=0$. The concavity of the problem implies $X^{*}>0$. This proves part (a).

Now, consider $X=Q / b$. Suppose that $U^{\prime \prime \prime}(W) \geqslant 0$ for all $W . C(Q /$ $b)>0$ follows directly. Also, $Q>0$ implies $A(Q / b) \leqslant 0$. Hence, $B(Q /$ $b) \geqslant 0$ by (16). Taken together, (14) is negative at $X=Q / b$. Hence, $X^{*}<Q / b$ due to the concavity of the problem. This proves part (b).

\section{References}

Adam-Müller, A., Wong, K.P., 2003. The impact of delivery risk on optimal production and futures hedging. European Finance Review 7, 459-477.

Ang, A., Chen, J., 2002. Asymmetric correlations of equity portfolios. Journal of Financial Economics 63, 443-494.

Ang, A., Chen, J., Xing, Y., 2006. Downside risk. Review of Financial Studies 19, 1191 1239

Bekaert, G., Wu, G., 2000. Asymmetric volatility and risk in equity markets. Review of Financial Studies 13, 1-42.

Benninga, S., Eldor, R., Zilcha, I., 1983. The optimal hedging in the futures market under price uncertainty. Economics Letters 13, 141-145.
Benninga, S., Eldor, R., Zilcha, I., 1984. The optimal hedge ratio in unbiased futures markets. Journal of Futures Markets 4, 155-159.

Benninga, S., Eldor, R., Zilcha, I., 1985. Optimal international hedging in commodity and currency forward markets. Journal of International Money and Finance 4 537-552.

Benninga, S., Oosterhof, C., 2004. Hedging with forwards and puts in complete and incomplete markets. Journal of Banking and Finance 28, 1-17.

Bodnar, G.M., Hyat, G.S., Marston, R.C., 1998. 1998 Wharton survey of financial risk management by US non-financial firms. Financial Management 27, 70-91.

Briys, E., Crouhy, M., Schlesinger, H., 1993. Optimal hedging in a futures market with background noise and basis risk. European Economic Review 37, 949-960.

Broll, U., Wahl, J.E., Zilcha, I., 1995. Indirect hedging of exchange rate risk. Journal of International Money and Finance 14, 667-678.

Brown, G.W., Toft, K.B., 2002. How firms should hedge. Review of Financial Studies $15,1283-1324$

Chang, E.C., Wong, K.P., 2003. Cross hedging with currency options and futures Journal of Financial and Quantitative Analysis 38, 555-574.

Chow, Y.-F., McAleer, M., Sequeira, J.M., 2000. Pricing of forward and futures contracts. Journal of Economic Surveys 14, 215-253.

DeMarzo, P.M., Duffie, D., 1995. Corporate incentives for hedging and hedge accounting. Review of Financial Studies 8, 743-771.

Doherty, N.A., Schlesinger, H., 1990. Rational insurance purchasing: Consideration of contract nonperformance. Quarterly Journal of Economics 105, 243-253.

Franke, G., Schlesinger, H., Stapleton, R.C., 2006. Multiplicative background risk Management Science 52, 146-153.

Froot, K.A., Scharfstein, S., Stein, J., 1993. Risk management: coordinating corporate investment and financing policies. Journal of Finance 68, 1629-1658.

Gollier, Ch., 1996. Optimum insurance of approximate losses. Journal of Risk and Insurance 63, 369-380.

Gollier, Ch., 2001. The Economics of Risk and Time. MIT Press, Cambridge, MA.

Graham, J.R., Rogers, D.A., 2002. Do firms hedge in response to tax incentives? Journal of Finance 57, 815-839.

Graham, J.R., Smith, C.W., 1999. Tax incentives to hedge. Journal of Finance 54 2241-2262.

Hentschel, L., Kothari, S.P., 2001. Are corporations reducing or taking risks with derivatives? Journal of Financial and Quantitative Analysis 36, 93-118.

Holthausen, D.M., 1979. Hedging and the competitive firm under price uncertainty. American Economic Review 69, 989-995.

Hong, Y., Tu, J., Zhou, G., 2007. Asymmetries in stock returns: statistical tests and economic evaluation. Review of Financial Studies 20, 1547-1581.

Ingersoll, J.E., 1987. Theory of Financial Decision Making. Rowman Littlefield, Totowa, NJ

Kimball, M.S., 1990. Precautionary saving in the small and in the large Econometrica 58, 53-73.

Korn, O., 2010. Risk management with default-risky forwards. Schmalenbach Business Review 10, 102-125.

Lence, S.H., 1995. On the optimal hedge under unbiased futures prices. Economics Letters $47,385-388$.

Lien, D., Tse, Y.K., 2002. Some recent developments in futures hedging. Journal of Economic Surveys 16, 357-396.

Mahul, O., 2002. Hedging in futures and options markets with basis risk. Journal of Futures Markets 22, 59-72.

Morellec, E., Smith, C.W., 2007. Agency conflicts and risk management. Review of Finance 11, 1-23.

Smith, C.W., Stulz, R.M., 1985. The determinants of firms' hedging policies. Journal of Financial and Quantitative Analysis 20, 391-405.

Stulz, R.M., 1984. Optimal hedging policies. Journal of Financial and Quantitative Analysis 19, 127-140.

Stulz, R.M., 1990. Managerial discretion and optimal financing policies. Journal of Financial Economics 26, 3-27.

SwissRe (Ed.), 2009. The Role of Indices in Transferring Insurance Risks to the Capital Markets. Sigma 4/2009, Zurich.

Wong, K.P., 2003. Currency hedging with options and futures. European Economic Review 47, 833-839.

Working, H., 1949. The theory of price of storage. American Economic Review 39, $1254-1262$ 